\title{
The Future of Cryopreservation in Assisted Reproductive Technologies
}

\author{
Ernesto Bosch ${ }^{1 *}$, Michel De Vos $^{2}$ and Peter Humaidan ${ }^{3,4}$ \\ ${ }^{1}$ Instituto Valenciano de Infertilidad, Valencia, Spain, ${ }^{2}$ Centre for Reproductive Medicine, Universitair Ziekenhuis Brussel, \\ Brussels, Belgium, ${ }^{3}$ The Fertility Clinic, Skive Regional Hospital, Skive, Denmark, ${ }^{4}$ Faculty of Health, Aarhus University, \\ Aarhus, Denmark
}

OPEN ACCESS

Edited by:

Marc Yeste

University of Girona, Spain

Reviewed by:

Giuliano Marchetti Bedoschi, University of São Paulo, Brazi

Paolo Rinaudo,

University of California, San Francisco,

United States

*Correspondence:

Ernesto Bosch

ernesto.bosch@ivirma.com

Specialty section: This article was submitted to

Reproduction,

a section of the journal

Frontiers in Endocrinology

Received: 12 April 2019

Accepted: 31 January 2020

Published: 20 February 2020

Citation:

Bosch E, De Vos M and Humaidan P (2020) The Future of Cryopreservation

in Assisted

Reproductive Technologies.

Front. Endocrinol. 11:67.

doi: 10.3389/fendo.2020.00067
Societal changes and the increasing desire and opportunity to preserve fertility have increased the demand for effective assisted reproductive technologies (ART) and have increased the range of scenarios in which ART is now used. In recent years, the "freeze-all" strategy of cryopreserving all oocytes or good quality embryos produced in an IVF cycle to transfer later-at a time that is more appropriate for reasons of medical need, efficacy, or desirability - has emerged as an accepted and valuable alternative to fresh embryo transfer. Indeed, improvements in cryopreservation techniques (vitrification) and the development of more efficient ovarian stimulation protocols have facilitated a dramatic increase in the practice of elective frozen embryo transfer (eFET). Alongside these advances, debate continues about whether eFET should be a standard treatment option available to the whole IVF population or if it is important to identify patient subgroups who are most likely to benefit from such an approach. Achieving successful outcomes in ART, whether by fresh or frozen embryo transfer, is influenced by a wide range of factors. As well as the efficiency of IVF and embryo transfer protocols and techniques, factors affecting implantation include maternal aging, sperm quality, the vaginal and endometrial microbiome, and peri-implantation levels of serum progesterone. The safety of eFET, both during ART cycles and on longer-term obstetric and neonatal outcomes, is also an important consideration. In this review, we explore the benefits and risks of freeze-all strategies in different scenarios. We review available evidence on the outcomes achieved with elective cryopreservation strategies and practices and how these compare with more traditional IVF cycles with fresh embryo transfers, both in the general IVF population and in subgroups of special interest. In addition, we consider how to optimize and individualize "freeze-all" procedures to achieve successful reproductive outcomes.

Keywords: oocyte cryopreservation, embryo cryopreservation, freeze-all, elective frozen embryo transfer (eFET), high responders, ovarian hyperstimulation syndrome (OHSS), polycystic ovary syndrome (PCOS), preimplantation genetic testing (PGT)

\section{INTRODUCTION}

Increasing demand for assisted reproductive technologies (ART) and improvements in cryopreservation techniques are re-shaping the therapeutic landscape in fertility treatment. Indications for ART are expanding as a result of societal changes and increasing desire and opportunity to preserve fertility, for example for "social" reasons in women wishing to improve their chances of conception at an older age, or for medical reasons such as preservation of oocytes prior to cytotoxic anticancer therapy. 
Changes in and increased use of ART protocols and procedures have been fueled recently by the development of more efficient ovarian stimulation protocols-for example, modified luteal phase support after gonadotrophin-releasing hormone $(\mathrm{GnRH})$ agonist triggers in $\mathrm{GnRH}$ antagonist protocols (1) - and new methods of cryopreservation (vitrification) as an alternative to the more traditional method of slow freezing $(2,3)$.

These advances, alongside growing understanding of the factors that can affect the outcomes of ART, are leading to continuing improvement in reproductive outcomes. Important factors that influence outcomes of ART include maternal aging (4) and luteal phase progesterone levels (5), as well as newly recognized confounders such as sperm DNA fragmentation (6), and the vaginal and endometrial microbiome (7).

The first human pregnancy from a frozen-thawed embryo was reported in 1983 and the first live birth in $1984(8,9)$. The strategy to cryopreserve all good quality embryos produced in a fresh cycle and to transfer these embryos in subsequent natural or artificially prepared cycles, has been coined a "freezeall" strategy (10). This strategy, alternatively named "freezeonly," first appeared in the literature over 20 years ago. The earliest publications described its application in protocols in which implantation is deferred in order to avoid ovarian hyperstimulation syndrome (OHSS) $(11,12)$, and is increasingly being used in preimplantation genetic testing (PGT) (13). Pioneers of elective cryopreservation and postponed embryo transfer applied the term "segmentation" of in vitro fertilization (IVF) treatments, where ovarian stimulation and oocyte/embryo retrieval is disconnected from the subsequent process of embryo transfer (14); a newer term that perhaps better represents the entire process is elective frozen embryo transfer (eFET) (15).

In this article, we will review perspectives on some of the latest advances, strategies, and practices in ART cycles using elective cryopreservation of embryos, and by extension, cryopreservation of oocytes, and whether these developments are likely to bring improvement to IVF outcomes. We will consider how to optimize reproductive outcomes from fresh and frozen embryo transfers, and how to optimize and individualize the "freeze-all" procedure, presenting clinical data demonstrating which patient populations or situations may benefit from this strategy.

\section{CRYOPRESERVATION TODAY}

As a result of improvements in ART, and particularly in the performance of cryopreservation programs, the practice of freezing oocytes or freezing good quality embryos for subsequent FET at a time that is more appropriate for reasons of OHSS prevention, medical issues, efficacy, or desirability has increased dramatically in recent years.

A survey conducted by the European IVF Monitoring (EIM) consortium of the European Society of Human Reproduction and Embryology (ESHRE) between 2010 and 2014 reported a total of 34,705 oocyte cryopreservation cycles across 17 responding countries with available data (out of 34 countries included) (16). Overall, the number of oocyte cryopreservation cycles reported increased continuously during the 5 -year period. However, the quality of data is variable and imprecise, highlighting a need for more rigorous national registries designed to collect detailed information on indications, usage, hormonal priming protocols, safety, and efficiency of reproductive cryopreservation of both oocytes and embryos (e.g., yields per cycle and per indication). More recently, in a separate annual survey of European ART data, the EIM group has added a question concerning the use of cryopreserved oocytes in ART cycles (17).

European data on embryo cryopreservation cycles are sparse, but data from the US Centers for Disease Control and Prevention show that the proportion of embryo transfers derived from freeze-all cycles is increasing-from around 20\% in 2005 to almost $50 \%$ in 2014-while the proportion of fresh embryo transfer procedures following IVF and intracytoplasmic sperm injection (ICSI) decreased correspondingly (Figure 1) (18). Editorials published in 2013 proposed that eFET would become accepted as the gold standard practice in $\operatorname{IVF}(19,20)$, although the evidence to support this claim at that time was based mostly on pooled observational data and only limited data from randomized trials. More studies have been conducted recently, and to date, 11 randomized controlled trials comparing eFET and fresh ET have been published (21-31).

\section{Indications for Cryopreservation in ART Practice}

Indications for cryopreservation in ART can be distinguished between elective (patient's choice) and non-elective (medical reasons) (Table 1). Although cryopreservation of embryos or oocytes was originally reserved for women with medical indications and no other fertility options, its use has expanded to include scenarios for elective cryopreservation, most commonly oocyte donation (32), and social oocyte freezing $(33,34)$. Patients may also choose to undertake clinical oocyte freezing, where a larger batch of oocytes is collected in consecutive ovarian stimulation cycles to increase the opportunities for and likelihood of future IVF success, particularly if there has been recurrent implantation failure $(35,36)$. Fertility preservation in transgenders is another area attracting increasing interest $(37,38)$. Finally, an option for males who wish to postpone parenthood is an elective sperm cryopreservation at a young age ( $<40$ years) to avoid the age-dependent DNA damage seen in males above the age of 40, which significantly increases the risk of passing agedependent monogenic and multifactorial diseases on to the offspring (39).

The use of oocyte cryopreservation tends to avoid the moral objections or legal restrictions that can be associated with embryo cryopreservation and storage, as well as the disputes that can arise if a couple later separates (16), and provides a feasible option for women who do not wish to cryopreserve embryos $(40,44)$. Nevertheless, embryo cryopreservation is an established technique and there is some evidence from large observational studies that implantation and pregnancy rates are higher from frozen-thawed embryos than when embryos derived from frozen oocytes are used $(40,49)$. PGT-A is the main medical reason for elective embryo cryopreservation (27) and allows time for 


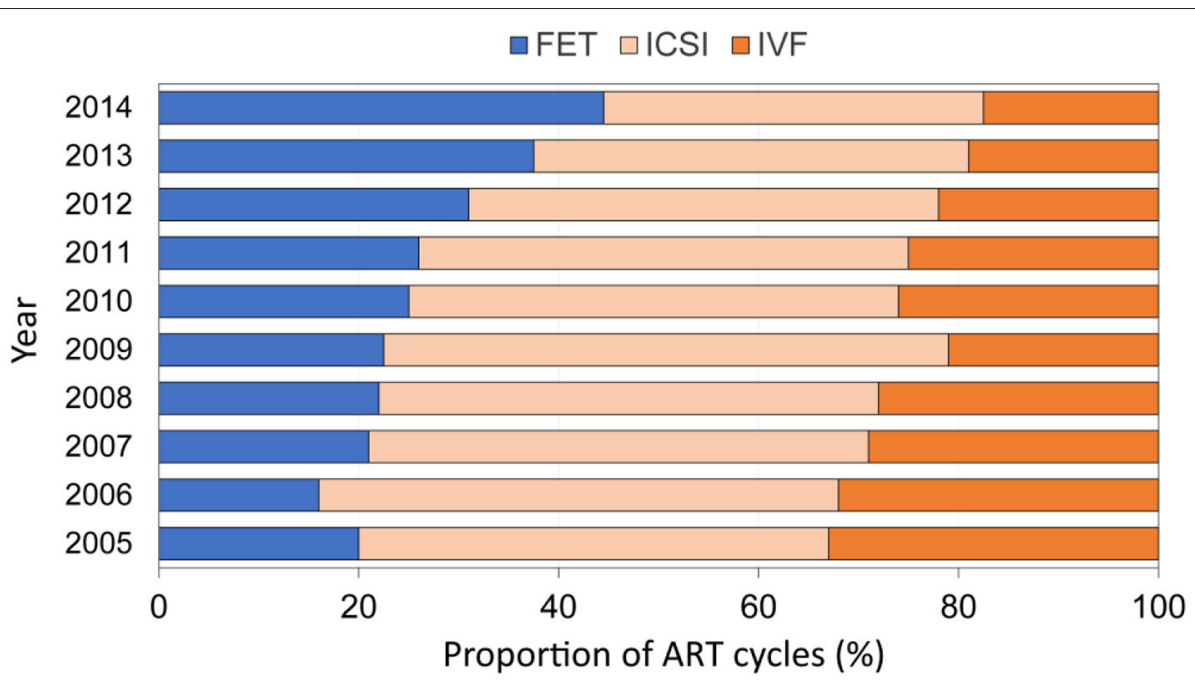

FIGURE 1 | Proportion of FET cycles among all ART cycles reported by year in the United States (2005-2014; US Centers for Disease Control and Prevention). Adapted from Groenewoud et al. (18). FET, frozen embryo transfer; ICSI, intracytoplasmic sperm injection; IVF, in vitro fertilization.

a suitable euploid embryo to be identified for transfer. Other situations presenting a medical reason for cryopreservation to allow embryo implantation in a later cycle are elevated progesterone in the late follicular phase (suggested to have a negative impact on pregnancy rates) (45-47) and prevention of OHSS, a potentially life-threatening complication of ovarian stimulation in IVF cycles $(25,48)$.

There may be various reasons other than medical to prefer eFET as a first-choice strategy in the clinic. Although available published evidence (reviewed later) shows that eFET has better results than fresh embryo transfer only in women with polycystic ovary syndrome (PCOS), high responders, and in the setting of PGT-A (15), FET performs no worse than fresh embryo transfer in normal responders; therefore, there is no need to fear the practice of cryopreservation.

The following sections explore considerations for the use of freeze-all strategies in different scenarios.

\section{FREEZE-ALL IN ART: WHAT DO WE NEED TO KNOW?}

An interesting clinical perspective on the strengths, weaknesses, opportunities, and threats associated with cryopreservation was published recently (50). The growing acceptance that cryopreservation is becoming a substantial part of ART practice raises a number of questions. Is it safe? Are there any longterm health consequences? Is it efficient? Do we need to re-design ovarian stimulation protocols to enhance efficiency compared with fresh embryo transfers? These and other topics are addressed below.

\section{How Many Oocytes Do We Need?}

There is no substitute for having a sufficient number of oocytes. Two large retrospective studies have demonstrated an association between oocyte number and cumulative live birth rate (CLBR) in ART. In fresh embryo transfers, the live birth rate plateaued at a level of 15 oocytes (51), whereas data from vitrification programs showed that CLBR steadily increased with the number of oocytes and no plateau was observed (52). Thus, the higher numbers of oocytes retrieved in high responders will result in higher CLBR. Whether the follicular output rate of a normal responder can be boosted in order to convert a normal responder into a high responder, and whether this will improve CLBR, are more controversial.

The Goldman model for social freezing calculates the probability of live birth for social freezers depending on the age at which they had their oocytes cryopreserved and the number of cryopreserved oocytes, and clearly demonstrates that a higher number of oocytes is very important for efficiency (53). The largest published cohort of freeze-all outcomes is in Chinese women, mostly young patients with tubal pathology, who also had increasing CLBR with higher numbers of oocytes; with $\geq 16$ oocytes, a CLBR of more than $50 \%$ was achieved in all age groups after one freeze-all cycle (54).

\section{How Do We Optimize Mature Oocyte Yield and Oocyte Quality?}

The optimum ovarian stimulation protocol for reproductive cryopreservation needs to be safe, convenient, and to achieve maximum ovarian response. This is particularly important for women who only have one chance to cryopreserve their oocytes, for example prior to cancer chemotherapy. Experience from the ART clinic suggests that the $\mathrm{GnRH}$ antagonist protocol followed by a GnRH agonist trigger is the shortest, safest, and most convenient stimulation protocol to obtain good quality oocytes and can give a maximum ovarian response in these patients (55).

\section{At What Follicle Size Should We Trigger Ovulation to Achieve the Highest Proportion of Good Quality Mature Oocytes?}

Data from a non-interventional, retrospective analysis of 165 Vietnamese women show that follicles of between 12 and $19 \mathrm{~mm}$ 
TABLE 1 | Indications for cryopreservation in ART practice.

\begin{tabular}{|c|c|c|}
\hline & Elective & Non-elective \\
\hline Oocytes & $\begin{array}{l}\text { Oocyte donation, oocyte banking } \\
\text { Avoids the need to match donor's and recipient's cycles, and addresses } \\
\text { demand for donor oocytes, thereby alleviating waiting lists (32) } \\
\text { Social freezing } \\
\text { Allows women wishing to defer childbearing to preserve their fertility in } \\
\text { anticipation of age-related fertility decline }(33,34) \\
\text { Oocyte cryopreservation can provide a feasible alternative where embryo } \\
\text { cryopreservation is not an option because of religious, moral or ethical } \\
\text { objections, or restrictive legislation (40) } \\
\text { clinical oocyte freezing } \\
\text { Accumulation of oocytes to increase likelihood of future success in cases of } \\
\text { poor responders or recurrent implantation failure (35, 36), or to increase } \\
\text { their availability for PGT (16) } \\
\text { Transgenders } \\
\text { In the case of female to male change, provides the opportunity to preserve } \\
\text { oocytes for future fertilization by a partner or sperm donor (37, 38) }\end{array}$ & $\begin{array}{l}\text { Medical oocyte freezing } \\
\text { In women about to undergo gonadotoxic treatment for cancer or other } \\
\text { conditions, or with a medical pathology that impairs fertility, such as severe } \\
\text { endometriosis (41) or genetic conditions including Turner's syndrome (42) } \\
\text { Incidental oocyte freezing } \\
\text { Emergency freezing in IVF when sperm is not available on the day of oocyte } \\
\text { retrieval (43) } \\
\text { Storage of "spare" oocytes during IVF (44) }\end{array}$ \\
\hline Embryos & $\begin{array}{l}\text { Preimplantation genetic testing (PGT) } \\
\text { PGT is facilitated by the opportunity to use the freeze-all strategy for storing } \\
\text { embryos for transfer in subsequent cycles after testing (27) } \\
\text { Patient's or physician's preference } \\
\text { The ability to store surplus embryos can reduce the number of embryos } \\
\text { transferred during a fresh cycle and thus minimize the risk of multiple } \\
\text { pregnancy, reduce the need for repeated stimulation cycles, and increase } \\
\text { cumulative pregnancy rates (44) }\end{array}$ & $\begin{array}{l}\text { Elevated progesterone } \\
\text { Elevated progesterone in the late follicular phase has a negative impact on } \\
\text { pregnancy rate, although the reasons for this are not entirely clear }(45-47) \\
\text { Avoidance of OHSS } \\
\text { Embryos may be cryopreserved rather than proceeding with a fresh embryo } \\
\text { transfer to allow ovarian recovery and thus prevent OHSS when excess } \\
\text { follicle development has occurred following ovarian stimulation in the IVF } \\
\text { cycle }(25,48)\end{array}$ \\
\hline
\end{tabular}

in diameter on the day of GnRH agonist trigger are most likely to yield mature oocytes on the day of oocyte retrieval and to lead to top-quality embryos (56). Balancing optimum follicle size and day of trigger is a critical decision, as a delay in triggering can lead to serum progesterone elevation (56), which is known to reduce implantation rates following fresh embryo transfer $(47,57)$.

\section{What Is the Impact of Elevated Progesterone in the Late Follicular Phase on Oocyte Quality?}

Two studies have demonstrated that there is no negative impact from elevated serum progesterone in the late follicular phase on oocyte quality or ongoing pregnancy rates in recipients of donated oocytes $(58,59)$. However, in a retrospective study of 3,400 cycles, the proportion of transferrable embryos among total embryos decreased as progesterone levels increased, and elevated late follicular-phase serum progesterone had a negative impact on CLBR after fresh ET and FET in IVF patients (60). According to a recent systematic review, elevated follicular fluid levels of progesterone may not be deleterious for oocyte quality (61).

\section{Random-Start Controlled Ovarian Stimulation (RSCOS)}

In the setting of cryopreservation, where there is no need for a fresh transfer in the same cycle, the cycle phase is not critical. The concept of "ovarian follicular waves" (62)-the existence of multiple follicular waves within one menstrual cycle-is more relevant for cryopreservation protocols and allows us to start the stimulation of the ovaries at any part of the cycle; there is no difference in oocyte number if stimulation is started in the luteal phase or the follicular phase. Currently, RSCOS is mainly performed in emergency oocyte cryopreservation in cancer patients (63-66), and less frequently in elective oocyte cryopreservation (67). New avenues will be explored in IVF patients. An example is an ongoing late follicular phase stimulation start project being conducted in Brussels (68). It has been clearly shown that the probability of an oocyte to provide a euploid blastocyst is the same for eggs obtained from the luteal phase as those obtained from the follicular phase (69). Another approach, particularly for poor responders, is to use dual stimulation. This can be helpful in situations in which one might want to save time by performing two stimulation treatments in a single menstrual cycle. Interestingly, recent data obtained in poor responders undergoing dual stimulation suggest that luteal phase stimulation results in more oocytes retrieved compared with follicular phase stimulation (70).

Another protocol modification compatible with a freezeall strategy is progestin-primed ovarian stimulation (PPOS), where the GnRH antagonist is replaced by a progestin, which can also suppress pituitary function. This strategy has been explored in China, where medroxyprogesterone or micronized progesterone have been used for preventing premature LH surges in women undergoing controlled ovarian hyperstimulation for IVF, with promising results so far $(71,72)$; however, longer-term safety data are required before this new strategy can be embraced. 


\section{Suboptimal Pituitary Response to GnRH Agonist Trigger}

An important pitfall of the GnRH agonist trigger ovarian stimulation protocol is that the endogenous luteinizing hormone (LH) rise can be suboptimal in some patients (post-trigger $\mathrm{LH}$ $\leq 15 \mathrm{mIU} / \mathrm{mL}$ at $12 \mathrm{~h}$ post trigger). The LH level on the day of $\mathrm{GnRH}$ agonist trigger appears to be the most useful marker for predicting a patient's risk of having a suboptimal response; for example, $25 \%$ of patients with undetectable $\mathrm{LH}$ levels on the day of trigger show a suboptimal surge, compared with $2.7 \%$ of the overall population of women undergoing IVF-ICSI cycles (73). A suboptimal pituitary response is also frequently observed in long-term contraceptive pill-users, significantly diminishing the mature oocyte yield (74). Use of a dual trigger of GnRH agonist combined with human chorionic gonadotropin (hCG) for final oocyte maturation has been successful in improving oocyte retrieval rates in $\mathrm{GnRH}$ agonist suboptimal responders $(75,76)$.

\section{Is the Freeze-All Strategy Cost-Effective?}

The quality and likelihood of implantation of frozen and fresh embryos are similar (77-79); however, data regarding costeffectiveness of a freeze-all approach are sparse. Moreover, published studies investigating this aspect did not adjust for ovarian response categories. Indeed, since women with high ovarian response may have improved clinical outcomes after the freeze-all approach compared to fresh transfer, additional direct costs of cryopreservation, additional medication and subsequent FET cycles may be compensated by the more favorable success rates. In a study from Italy, there was no difference in cost between fresh blastocyst transfer and the freeze-all strategy (per live birth); the extra costs of vitrification, endometrial priming, and monitoring were offset by the fewer embryo transfer procedures needed, due to the efficiency of the freeze-all strategy (80). Obstetric and neonatal costs were not measured in this study. The costeffectiveness of the freeze-all strategy was also demonstrated in a Brazilian study, in which treatment costs per ongoing pregnancy were significantly lower in freeze-all vs. fresh cycles (81).

When analyzing cost-effectiveness of the freeze-all and fresh transfer approaches, time-to-pregnancy should also be taken into account. Indeed, delay of embryo transfer in the freeze-all setting may heighten patient distress and anxiety accompanying an ART cycle. Nevertheless, even in a freezeall setting, the delays between oocyte retrieval and embryo transfer can be kept to a minimum, since several retrospective trials have shown that FET can be performed as soon as the oncoming cycle after oocyte pick-up, without compromising success rates (82-88). Finally, when comparing health economic aspects of a freeze-all strategy and fresh embryo transfer, one has to take into account that adverse obstetric and neonatal outcomes such as preterm delivery and low birth weight may have a long-term impact on cost; therefore, modeling is required to inform cost-effectiveness over an extended time horizon (89).

\section{Safety of Reproductive Cryopreservation}

Observations about the outcomes of reproductive cryopreservation in terms of effects on pregnancies and on neonates reveal several consistent findings. An increased risk of placental problems (such as placenta accreta), pregnancyinduced hypertension, and pre-eclampsia has been observed following FET (90-93), although a recent large randomized controlled trial found no differences in pre-eclampsia or hypertensive disorders between eFET and fresh embryo transfer when eFET was performed in the natural cycle (29). Compared with infants born after fresh embryo transfer, those born after FET had a lower risk of prematurity according to some studies (94-97), although other studies did not find any difference $(98,99)$. Infants born after FET have also been reported to have a lower risk of small-for-gestational age $(96,100,101)$, and a higher birthweight (102) than those born after fresh embryo transfer. Less consistent findings for FET vs. fresh embryo transfer outcomes include more (90), similar (101), or fewer (103) perinatal/neonatal deaths, and lower monozygotic twinning rates (104).

A recent meta-analysis provides new evidence about whether there are differences in terms of neonatal outcome following fresh or frozen embryo transfer cycles (Table 2) (105). Frozen cycles are associated with a lower risk of prematurity or having low birthweight, but a higher risk of high birthweights and, importantly, a higher risk also for hypertensive disorders of pregnancy $(105,106)$. For some neonatal outcomes there is no significant difference between frozen and fresh transfer strategies: antepartum hemorrhage, admission to the neonatal intensive care unit, congenital abnormalities, and perinatal mortalities (105).

Higher birthweight associated with FET has been observed in large epidemiological studies in the UK (100), and in Scandinavia $(92,107)$, and has been further analyzed in meta-analyses by Pinborg et al. $(108,109)$. However, it is not clear whether the FET process itself contributes to higher birthweight or if other factors are involved. Importantly, birthweight could be influenced by the endometrial preparation with estrogens for FET, as no difference in birthweight was seen when embryos were transferred in a natural cycle (29). The increased risk of being born large for gestational age after FET has been observed both after vitrification and after slow freezing, and cryostorage duration of vitrified blastocysts does not appear to affect pregnancy and neonatal outcomes (102). However, further research is required to understand the physiological mechanisms that contribute to the larger birthweight associated with FET.

The use of estrogens in endometrial priming protocols during artificial FET cycles has been proposed as an explanation for the increased risk of pre-eclampsia associated with FET (15), based on contrasting findings from two large randomized controlled trials. In the first study, 1,508 women with PCOS were randomized to fresh embryo transfer or to eFET, with eFET cycles performed after estradiol valerate priming (25). Women in the eFET group had a higher rate of pre-eclampsia than those who underwent fresh embryo transfer (4.4 vs. $1.4 \% ; P=$ $0.009)$ (25). A separate study $(N=2,157$; in which women with PCOS were excluded) found no differences in pre-eclampsia or 
TABLE 2 | Outcomes of FET vs. fresh embryo transfer in mothers and neonates.

\begin{tabular}{|c|c|c|c|c|c|}
\hline \multicolumn{2}{|c|}{ Favors FET } & \multicolumn{2}{|c|}{ Favors fresh embryo transfer } & \multicolumn{2}{|c|}{ No difference } \\
\hline Outcome & $\begin{array}{l}\text { FET vs. fresh embryo } \\
\text { transfer RR ( } 95 \% \mathrm{Cl})\end{array}$ & Outcome & $\begin{array}{l}\text { FET vs. fresh embryo } \\
\text { transfer RR ( } 95 \% \mathrm{Cl})\end{array}$ & Outcome & $\begin{array}{l}\text { FET vs. fresh embryo } \\
\text { transfer RR }(95 \% \mathrm{Cl})\end{array}$ \\
\hline $\begin{array}{l}\text { Small for gestational } \\
\text { age }\end{array}$ & $\begin{array}{c}0.61 \\
(0.56-0.67)\end{array}$ & Large for gestational age & $\begin{array}{c}1.54 \\
(1.48-1.61)\end{array}$ & $\begin{array}{l}\text { Antepartum } \\
\text { hemorrhage }\end{array}$ & $\begin{array}{c}0.82 \\
(0.66-1.03)\end{array}$ \\
\hline $\begin{array}{l}\text { Low birthweight } \\
(<2,500 \mathrm{~g})\end{array}$ & $\begin{array}{c}0.72 \\
(0.67-0.77)\end{array}$ & $\begin{array}{l}\text { High birthweight } \\
(>4,000 \mathrm{~g})\end{array}$ & $\begin{array}{c}1.85 \\
(1.46-2.33)\end{array}$ & Admission to NICU & $\begin{array}{c}0.99 \\
(0.84-1.18)\end{array}$ \\
\hline $\begin{array}{l}\text { Very low birthweight } \\
(<1,500 \mathrm{~g})\end{array}$ & $\begin{array}{c}0.76 \\
(0.69-0.82)\end{array}$ & $\begin{array}{l}\text { Very high birthweight } \\
(>4,500 \mathrm{~g})\end{array}$ & $\begin{array}{c}1.86 \\
(1.58-2.19)\end{array}$ & $\begin{array}{l}\text { Congenital } \\
\text { abnormalities }\end{array}$ & $\begin{array}{c}1.01 \\
(0.87-1.16)\end{array}$ \\
\hline $\begin{array}{l}\text { Preterm delivery } \\
\text { (<37 weeks) }\end{array}$ & $\begin{array}{c}0.90 \\
(0.84-0.97)\end{array}$ & $\begin{array}{l}\text { Hypertensive disorders of } \\
\text { pregnancy }\end{array}$ & $\begin{array}{c}1.29 \\
(1.07-1.56)\end{array}$ & Perinatal mortality & $\begin{array}{c}0.92 \\
(0.78-1.08)\end{array}$ \\
\hline $\begin{array}{l}\text { Very preterm delivery } \\
\text { (<32 weeks) }\end{array}$ & $\begin{array}{c}0.85 \\
(0.74-0.97)\end{array}$ & & & & \\
\hline
\end{tabular}

Summary results from cumulative meta-analyses. Adapted from Maheshwari et al. (105).

$\mathrm{Cl}$, confidence interval; FET, frozen embryo transfer; NICU, neonatal intensive care unit; $R R$, relative risk.

hypertensive disorders between eFET and fresh embryo transfer when eFET was performed in the natural cycle (29). Recent work has demonstrated that programmed cycles for FET were associated with higher rates of pre-eclampsia (110). The authors observed that programmed FET cycles, during which the corpus luteum is absent, are associated with impairment of the expected pregnancy-associated increase in central arterial compliance, probably because of absence of circulating vasoactive factors produced by the corpus luteum.

Another consideration is the direct effect of the cryopreservation process itself. According to published data, oocyte survival rates in young women who request planned oocyte cryopreservation for non-medical reasons are reassuringly high, with rates of $90 \%$ and higher (111). Furthermore, survival rates of oocytes vitrified using closed methods have been consistently higher than those of oocytes vitrified using open methods (112). Nevertheless, women should be informed that survival rates are age-dependent, reflecting age-related quality decline, and women above the age of 35 years should be counseled that $20 \%$ or more of vitrified oocytes may not survive the warming process (111).

One area of study is whether there is an epigenetic effect of the cryopreservation process. According to the hypothesis of the developmental origins of health and disease (DOHaD), cryopreservation of oocytes or embryos may disturb epigenetic mechanisms and by doing so, influence embryonic gene expression, which could result in altered development of the placenta and fetus in the early embryonic stages and cause changes in growth patterns and metabolic parameters. This could eventually lead to disease at later stages in life $(113,114)$. Hence, future follow-up studies of health in offspring conceived after oocyte and embryo cryopreservation are mandatory. Genome-wide analysis of placental miRNAs-important epigenetic regulators of gene expression-has demonstrated differentially expressed miRNAs in FET placentae compared with placentae from fresh embryo transfers, potentially contributing to increased birthweight and perinatal complications. There was no difference in expression between placentae from fresh embryo transfers vs. spontaneous pregnancies (115). The underlying mechanism is unclear, but these findings suggest this may be an important safety measure to explore in the longer term.

The impact of ART techniques on imprinting errors remains unclear, as the infertile population likely confers an independent risk factor for defects in expected epigenetic patterns (116). While some studies have observed an impact on bovine (117) and mouse embryos $(118,119)$, analysis of fresh vs. vitrified sibling human oocytes found that there was no difference in terms of maturation rates (i.e., epigenetic imprints) in the blastocysts after vitrified oocytes compared to fresh oocytes (120). Consistent with this finding, data from 1,027 children born after oocyte cryopreservation and 1,224 from fresh oocytes suggest that there is no increased risk of adverse obstetric and perinatal outcomes in children conceived with vitrified oocytes (121).

\section{FREEZE-ALL FOR ALL PATIENTS?}

Despite the recent steady increase in the use of eFET as a component of ART, debate continues about whether eFET should be a standard treatment option available to the overall IVF population or if it is important to identify patient subgroups who are most likely to benefit from such an approach.

The eFET strategy has been compared with fresh embryo transfer in several large randomized controlled trials $(22,23,25$, 27, 29, 30); among these, a significantly superior benefit for FET over fresh embryo transfer has only been proven in women with PCOS, high responders, and in the setting of PGT-A (15).

Early positive results for FET appeared to support a shift to a freeze-all strategy for an increasing proportion of patients. A randomized single-center study of 103 first-time IVF patients in the US reported rates of ongoing pregnancies of $78 \%$ compared with $51 \%$ after cryopreservation cycles and fresh embryo transfers, respectively $(P=0.0072)(23)$. However, there were a number of limitations and biases: a small number of patients, the effect of co-interventions (dual triggering) was not 
considered, and there were abnormally high pregnancy rates in the cryopreservation cycles. A study from Brazil comparing the outcomes of freeze-all cycles $(N=179)$ and fresh transfer cycles $(N=351)$ also showed significant improvements in terms of implantation rates and clinical and ongoing pregnancy rates when a freeze-all strategy was applied (122). However, the population undergoing the freeze-all strategy also had significantly higher progesterone levels on the day of ovulation trigger, suggesting that the two study groups were not directly comparable (122).

Other studies do not support the concept that a freezeall strategy is suitable for all patients. A retrospective study of 882 women aged 20-44 years undergoing their first or second IVF/ICSI cycle showed that there was no benefit on LBR of freeze-all vs. fresh transfer in normoovulatory women undergoing IVF (123). Patients with a risk of OHSS, high responders and women with high progesterone levels on the day of trigger were excluded from the study because those subgroups were already known to show improved outcomes with FET. Patients produced a normal oocyte yield (4-20 oocytes) in response to controlled ovarian stimulation and the results of embryo transfer showed that there were no differences for eFET vs. fresh embryo transfers in these normal responders in terms of implantation, clinical and ongoing pregnancies, and live births (123).

These findings have been confirmed recently in two large randomized controlled trials from China $(N=2,157)(29)$ and Vietnam $(N=782)(30)$. These studies show that for groups that are comparable in terms of ovarian stimulation protocol and dose, ovarian response, and late follicular progesterone levels, there is no benefit in LBR of eFET compared with fresh embryo transfer in normo-ovulatory women undergoing IVF. Importantly, in the Chinese study, the risk of women experiencing moderate or severe OHSS was significantly lower in the women who received the eFET strategy than in those who received fresh embryo transfers ( 0.6 vs. $2.0 \% ; P=0.005$ ) (29).

A new meta-analysis of 11 randomized trials including 5,379 patients who underwent IVF/ICSI reported a significantly higher LBR with eFET compared with fresh embryo transfer in the overall IVF/ICSI population [risk ratio (RR), 1.12; 95\% CI, 1.011.24], but no significant difference in CLBR (15). In subgroup analyses, the LBR benefit was only evident in hyper-responders (at high risk of developing OHSS; RR, 1.16; 95\% CI, 1.05-1.28) and in PGT-A cycles (RR, 1.55; 95\% CI, 1.14-2.10). There was no difference for LBR in normo-responders.

Beyond the potential risks associated with artificial cycle fresh embryo transfer in high responders, these findings suggest that in this population, there might be an impairment of endometrial receptivity due to a direct impact of high steroid levels, mainly progesterone, on endometrial maturation $(47,124)$.

The effect of FET on neonatal outcomes and the relative risks associated with frozen vs. fresh embryo transfers have been discussed previously in the section "Safety of Reproductive Cryopreservation." These findings suggest that the obstetric background of the patient should also be considered when making a decision about a fresh transfer or a freeze-all strategy.

\section{Indications in Which Freeze-All Is Beneficial}

Based on the findings reported above, there are two scenarios in which a freeze-all strategy is significantly superior to fresh embryo transfer.

\section{PCOS Patients and OHSS Prevention}

In high responders, in whom the risk of potentially lifethreatening OHSS in response to ovarian stimulation in IVF is well-known, the benefit of a freeze-all strategy has been demonstrated in a large $(N=1,508)$ randomized controlled trial in China (25). The LBR after first embryo transfer was $49.3 \%$ for eFET vs. $42.0 \%$ for fresh embryo transfer $(P=0.004)$. Importantly, the frequency of OHSS was significantly lower in eFET cycles vs. fresh transfer cycles $(1.3$ vs. $7.1 \%$; $P<0.001)$. These results support the recommendation of an eFET strategy in women with PCOS, in order to optimize the response whilst also minimizing the risk of OHSS.

\section{PGT-A Programs}

The development of PGT-A in the past years has been facilitated by the opportunity to use the eFET strategy for storing embryos for transfer in subsequent cycles. A successful fresh embryo transfer in this setting requires expanded blastocysts be available on the morning of day 5 , and for PGT results to identify a suitable euploid embryo in time for transfer on day 6. The freeze-all strategy allows time for PGT results to be obtained for a whole cohort of embryos, which also results in a higher proportion of patients reaching embryo transfer. Transfer of a suitable euploid embryo is performed in a subsequent cycle. Indeed, there is increasing evidence that, in terms of implantation and ongoing pregnancy rates and clinical outcomes, FET in a non-stimulated cycle may be superior to performing a fresh embryo transfer in a stimulated cycle $(122,125-128)$. In a randomized controlled trial in 179 patients undergoing IVF treatment and PGT-A, ongoing pregnancy rates ( 80 vs. $61 \% ; P=0.03$ ) and LBR (77 vs. $59 \% ; P=$ 0.04 ) were significantly higher in the eFET group compared with those receiving fresh embryo transfer (27).

In addition to PCOS and PGT-A, there are other situations in which eFET can provide the opportunity to delay embryo transfer when conditions during the ovarian stimulation cycle may not be optimal for implantation.

\section{Follicular Phase Progesterone Elevation}

Progesterone increase at the end of stimulation, if above a certain threshold level ( $\sim 4-5 \mathrm{nmol} / \mathrm{L}[\sim 1.25-1.5 \mathrm{ng} / \mathrm{mL}])$, led to a sharp decrease in implantation rates following fresh embryo transfer in some studies $(47,57)$, but this was not reported in others $(129,130)$. If all of the embryos are frozen and FET performed in a subsequent natural or endometrial preparation cycle, results have been reported to be better (57). As described above, the impact of high progesterone seems to be on the endometrium, only and, therefore, on implantation in the stimulation cycle whereas the quality of eggs collected for cryopreservation is not affected $(58,59)$. 


\section{Concomitant Endometrial or Tubal Pathology}

The presence of endometrial polyps or a hydrosalpinx during the ovarian stimulation procedure is another scenario that can affect uterine receptivity $(131,132)$, and in the past would have resulted in an impaired or canceled ART cycle. With cryopreservation, the complication can be overcome by freezing the embryos, resolving the pathology, and transferring the frozen embryo in a subsequent cycle.

\section{Adenomyosis}

Results of a small study showed a non-significant trend to improved outcomes with FET in women with adenomyosis (133), but large randomized clinical trials are needed to confirm this hypothesis.

\section{Slow Embryo Development}

A successful embryo transfer and implantation requires embryo maturation to be at a synchronous stage with endometrium receptivity. In patients in whom embryo development does not reach blastocyst stage by day 5 , transfer is delayed; implantation rates on day 6 are 15-18\% lower compared with day 5 transfer (134). Alternatively, if embryos are frozen and transferred in the second cycle, outcomes will be improved compared with fresh transfer by avoiding the dys-synchrony between an endometrium that is too advanced vs. an underdeveloped embryo.

The freeze-all strategy has also allowed for the development of new ovarian stimulation protocols that optimize oocyte retrieval but do not allow for transfer within the same cycle-these include RSCOS, PPOS, and dual stimulation, as described above in the section "How Do We Optimize Mature Oocyte Yield and Oocyte Quality?" In these cases, cryopreservation is necessary because the endometrium will be out of phase for implantation within the same cycle.

\section{OPTIMIZING THE FROZEN EMBRYO TRANSFER CYCLE}

\section{Methods of Freeze-All}

The first successful pregnancies from frozen embryos in the 1980s used slow-freeze and rapid-thaw cryopreservation techniques. Slow freezing results in a liquid changing to a solid state, and technical issues-particularly with oocytessuch as intracellular ice formation and disrupted intracellular morphology led to low success rates and slow progress in the field, despite attempts to improve components of the process, including cryoprotectants, equilibration timing, cooling rates, and freezing devices [reviewed by Argyle et al. (44)]. More recently, vitrification methods have been developed to overcome these issues. Vitrification uses higher concentrations of cryoprotective additives and ultra-rapid cooling, lowering the risk of ice nucleation and crystallization to produce a non-crystalline amorphous solid. It is now established that vitrification is much more efficient than slow freezing, regardless of whether they are cleavage stage embryos or blastocysts (135), and that the stage of embryo development at which embryos are frozen does not have an impact on survival rates or implantation rates (78). Vitrification has made oocyte cryopreservation a reality and allowed it to become an established option for ART (44). The results of four randomized controlled trials $(32,136-$ 138) showing that fertilization and pregnancy rates after IVF with vitrified oocytes were similar to those using fresh oocytes led to the adoption of oocyte cryopreservation in medical guidelines for ART (40).

\section{Role of Progesterone at Time of Implantation}

Data from non-human studies and studies of spontaneous conception cycles and frozen-thawed embryo transfer cycles indicate that in the mid-luteal phase, there is a relatively narrow window of serum progesterone levels within which implantation is most likely to occur $(5,139,140)$. In a prospective multicenter cohort study of 602 women undergoing IVF/ICSI fresh blastocyst transfers an optimal mid-luteal progesterone range of 150-250 $\mathrm{nmol} / \mathrm{L}$ (47-79 $\mathrm{ng} / \mathrm{mL}$ ) secured the highest LBR (54\%), compared to 42 and $38 \%$ at progesterone levels $<150 \mathrm{nmol} / \mathrm{L}(<47 \mathrm{ng} / \mathrm{mL})$ and $>400 \mathrm{nmol} / \mathrm{L}$ (>126 ng/mL), respectively (5). For early luteal progesterone and pregnancy rate, there was a bigger difference: the highest pregnancy rate $(73 \%)$ was achieved with early luteal progesterone of $60-100 \mathrm{nmol} / \mathrm{L}(19-31 \mathrm{ng} / \mathrm{mL})$; outside this range, pregnancy rates were significantly lower, particularly at high levels of progesterone $(>400 \mathrm{nmol} / \mathrm{L}[>126 \mathrm{ng} / \mathrm{mL}]$ : pregnancy rate $35 \%$; difference $-38 \% ; P=0.01$ ). All women in this study received the same vaginal luteal support regimen.

Adequate circulating progesterone levels at embryo transfer are important to upregulate endometrial genes not only for successful implantation, but also during early pregnancy (141). Apart from regulating the window of implantation, progesterone increases endometrial vascularization and works as an immune modulator to securing the onward growth of the early implant (141). Hence, high rates of early pregnancy loss are seen when progesterone supplementation is suboptimal during artificial endometrial preparation (142). A series of three studies evaluating increasing levels of luteal support in an ovarian stimulation protocol of GnRH agonist trigger with fresh transfer illustrates the relationship between mid-luteal progesterone and pregnancy rates (Table 3) (1, 143, 144). Across the three studies, there was substantial decrease in early pregnancy loss and an increase in ongoing pregnancy rate as mid-luteal progesterone increased. Based on these collective findings, a lower cut-off level of around $75 \mathrm{nmol} / \mathrm{L}(24 \mathrm{ng} / \mathrm{mL})$ progesterone at oocyte pick-up was defined to secure the highest clinical pregnancy rate $(\sim 40 \%)$, which is in line with the expected ongoing pregnancy rate at week 12 in a single embryo transfer program in those centers.

Elevated progesterone in the late follicular phase has also recently become recognized as a factor that may impact implantation in fresh embryo transfer cycles and is known to have a negative impact on pregnancy rate (45-47). There is currently no evidence to suggest that results in FETs are affected by high progesterone levels in the follicular phase.

Whether serum measurements of progesterone can predict endometrial receptivity has been explored in a recent study in healthy women undergoing modeled endometrial cycles with varying intramuscular (IM) progesterone dosing $(2.5,5,10$, or 40 $\mathrm{mg}$ /day) after $\mathrm{GnRH}$ down-regulation and transdermal estradiol 
TABLE 3 | Reproductive outcomes after embryo transfer in cycles with different levels of luteal phase progesterone support (1, 143, 144).

\begin{tabular}{|c|c|c|c|c|c|}
\hline References & $\begin{array}{c}\text { Progesterone at } \\
\text { OPU }+7 \text { days, } \mathrm{nmol} / \mathrm{L} \\
(\mathrm{ng} / \mathrm{mL})\end{array}$ & $\begin{array}{l}\text { Positive hCG per } \\
\text { embryo transfer, } \%\end{array}$ & $\begin{array}{l}\text { Pregnancy } \\
\text { loss, \% }\end{array}$ & $\begin{array}{c}\text { Clinical } \\
\text { pregnancy, \% }\end{array}$ & Luteal phase support \\
\hline Humaidan et al. (143) & $\begin{array}{l}39 \pm 30 \\
(12 \pm 9)\end{array}$ & $\begin{array}{c}29 \\
(14 / 48)\end{array}$ & $\begin{array}{c}79 \\
(11 / 14)\end{array}$ & $\begin{array}{c}6 \\
(3 / 48)\end{array}$ & Progesterone vaginal gel (90 mg/day) \\
\hline Humaidan et al. (144) & $\begin{array}{c}74 \pm 52 \\
(23 \pm 16)\end{array}$ & $\begin{array}{c}48 \\
(63 / 130)\end{array}$ & $\begin{array}{c}21 \\
(13 / 63)\end{array}$ & $\begin{array}{c}38 \\
(50 / 130)\end{array}$ & $\begin{array}{l}\text { hCG } 1,500 \mathrm{IU} \text { on the day of OPU plus } \\
\text { progesterone vaginal gel } 90 \mathrm{mg} \text { per day }\end{array}$ \\
\hline Humaidan et al. (1) & $\begin{array}{l}440 \pm 25 \\
(138 \pm 8)\end{array}$ & $\begin{array}{c}43 \\
(47 / 110)\end{array}$ & $\begin{array}{c}9 \\
(4 / 47)\end{array}$ & $\begin{array}{c}39 \\
(43 / 110)\end{array}$ & $\begin{array}{l}\text { hCG } 1,500 \mathrm{IU} \text { on the day of OPU and at } \\
\mathrm{OPU}+5 \text { days plus progesterone } \\
\text { vaginal gel } 90 \mathrm{mg} / \text { day }\end{array}$ \\
\hline
\end{tabular}

EPL, early pregnancy loss; GnRH, gonadotrophin-releasing hormone; hCG, human chorionic gonadotropin; OPU, oocyte pick-up; P, progesterone.

(145). Endometrial samples taken on day 10 of progesterone revealed apparently normal receptive histology in all except the lowest dose group, in which morphological delay was evident. Thus, most samples appeared to show a receptive endometrium. This was despite serum progesterone levels reaching the typical mid-secretory phase range only in the highest dose group. The same study looked at microarray analysis of endometrial gene expression as a measure of functional response to progesterone and found a significantly different pattern. Only patients that had the highest serum progesterone showed an endometrial gene expression profile comparable to natural cycle control patients, which is compatible with a receptive endometrium; a consistently altered functional response was seen in both of the lower dose groups (145). These results suggest that histology does not provide a reliable indication of endometrial receptivity, but gene expression profiles indicate that insufficient progesterone in the luteal phase leads to poor endometrial functionality.

\section{How Do We Prepare the Endometrium for FET? \\ Natural or Artificial Cycles for FET (NC-FET vs. AC-FET)}

Once the decision to cryopreserve has been made, there is an ongoing debate about how to prepare the patient for embryo transfer, and whether a natural cycle or an artificial endometrial preparation cycle is preferred. Based on the published literature, the most common protocols used for FET preparation are a natural cycle with or without hCG trigger, or endometrial preparation with estrogen/progesterone hormone therapy with or without GnRH agonist suppression (146). A recent metaanalysis shows a non-significant trend in favor of natural cycles for better clinical and ongoing pregnancy rates and LBR [LBR odds ratio, $1.21 ; 95 \% \mathrm{CI}, 0.96-1.51 ; P=0.10]$ (18). The recently updated Cochrane systematic review also concluded that there is no difference in LBRs following different methods of endometrial preparation for FET (146). However, the quality of available evidence used in these analyses is poor, being derived predominantly from retrospective studies; therefore, prospective randomized studies are needed before any firm conclusions can be made about the superiority of one protocol over another.

A number of additional questions remain to be resolved: the optimal monitoring regimen for the natural cycle FET has not yet been determined; the routine used of luteal phase support in the natural cycle increases treatment burden, but it is not clear whether it is beneficial; in artificial cycles, the relative benefits of various routes of estrogen and progesterone administration need to be evaluated; the minimum duration of estrogen and progesterone supplementation also needs further clarification. Some of these questions are explored in studies described below.

\section{What Is the Evidence for Giving Luteal Phase Progesterone Support for Embryo Transfer in a Natural Cycle?}

A randomized controlled trial of 435 women undergoing embryo transfer in natural cycles demonstrated a significantly higher LBR group in the group who received vaginal progesterone $(400 \mathrm{mg}$ twice a day from the day of embryo transfer) compared with those who received no progesterone support (30 vs. $20 \% ; P=0.027$ ) (147). In a retrospective cohort study of 228 consecutive women who received FET in modified natural cycles, those treated with progesterone vaginal gel (Crinone gel $8 \%$; $90 \mathrm{mg}$ /day from 2 days after hCG) experienced a significantly lower miscarriage rate $(8.5$ vs. $24.1 \% ; P=0.044)$ and achieved a significantly higher LBR (37.2 vs. $24.1 \% ; P=0.041$ ) than the no progesterone group (148).

\section{Is the Route of Administration of Progesterone Important for Artificial Endometrial Preparation?}

In a planned interim analysis of a three-arm randomized controlled trial in women undergoing FET with different modes of progesterone replacement, vaginal progesterone alone was found to be inferior to protocols containing IM progesterone (149). A total of 645 FET cycles were randomized to: IM progesterone $50 \mathrm{mg}$ per day; IM progesterone every 3 days with vaginal progesterone $200 \mathrm{mg}$ per day; or vaginal progesterone $200 \mathrm{mg}$ every $12 \mathrm{~h}$. The group receiving only vaginal progesterone had a significantly higher miscarriage rate and a significantly lower ongoing pregnancy rate than the other two groups, and randomization to the vaginal progesterone group was discontinued as a result of these findings. The study is ongoing to compare the two IM progesterone protocols.

\section{Optimizing Mid-luteal Progesterone}

In the series of three studies evaluating increasing levels of progesterone support $(1,143,144)$ [described above in the section 
"Role of Progesterone at Time of Implantation"], modified luteal phase support comprised vaginal progesterone gel $90 \mathrm{mg} /$ day alone or with the addition of one or two doses of 1,500 IU hCG around day of oocyte pick-up, with corresponding increases in progesterone levels (Table 3 ). The optimum range of midluteal progesterone levels was achieved with the intermediate regimen of progesterone vaginal gel plus a single dose of hCG (144); the addition of a second hCG dose in the third study (1) resulted in a higher mid-luteal progesterone $(440 \mathrm{nmol} / \mathrm{L}$; $138 \mathrm{ng} / \mathrm{mL}$ ) and a significant reduction in early pregnancy loss rates, whereas the ongoing pregnancy rate was similar to that seen in the previous study.

\section{What Is the Impact of Serum Progesterone Levels in Estrogen/Progesterone Hormone Therapy Cycles for FET?}

Results of a retrospective cohort study of 346 women who underwent FET after endometrial preparation with estradiol and progesterone vaginal gel $90 \mathrm{mg}$ (Crinone) showed that using progesterone twice a day rather than once a day was associated with significantly better implantation rates (20.2 vs. $7.6 \% ; P=0.0001)$ and delivery rates $(20.5$ vs. $8.7 \% ; P=0.002)$, and significantly lower early pregnancy loss rates ( 43.7 vs. $67.4 \%$; $P=0.014)$ (139).

In another study, low serum progesterone levels on the day of transfer were associated with lower ongoing pregnancy rates in a total of 211 oocyte recipients in a standard hormone therapy FET program with an artificial endometrial preparation cycle of oral or transdermal estradiol and vaginal micronized progesterone ( $400 \mathrm{mg} / 12 \mathrm{~h}$ from 5 days before embryo transfer) (142). Even though these patients all received the same regimen, there was a wide range of progesterone levels on the day of transfer, suggesting that vaginal progesterone was absorbed at different rates or to different extents among individual women. There was a corresponding variation in reproductive outcomes. Patients with the lowest serum progesterone $(<29 \mathrm{nmol} / \mathrm{L}$ $[9.2 \mathrm{ng} / \mathrm{mL}])$ on the day of embryo transfer achieved significantly lower pregnancy rates $(33 \%)$ than those with the highest levels ( $\geq 50 \mathrm{nmol} / \mathrm{L}[\geq 15.8 \mathrm{ng} / \mathrm{mL}] ; 51 \% ; P=0.016)$; in fact, the most favorable results across all outcomes were achieved in the 3 rd-quartile group (progesterone level range $\sim 38-50 \mathrm{nmol} / \mathrm{L}$ [ 11.8-15.7 ng/mL]) (142). These findings were supported by a recent retrospective study in which serum progesterone $<32$ $\mathrm{nmol} / \mathrm{L}(<10 \mathrm{ng} / \mathrm{mL})$ was associated with significantly lower pregnancy rates (34 vs. $48 \% ; P=0.04$ ) and LBR (17 vs. $31 \% ; P=0.01)$ compared with progesterone $\geq 32 \mathrm{nmol} / \mathrm{L}$ $(\geq 10 \mathrm{ng} / \mathrm{mL})(150)$.

A new study-again in women undergoing a standard hormone therapy FET program, with transfer of high quality blastocysts-has also shown correlation between ongoing clinical pregnancy and progesterone levels (151). In agreement with Labarta et al. (142), the progesterone level for the best ongoing pregnancy rate $(58 \%$ at week 12$)$ was $\geq 35 \mathrm{nmol} / \mathrm{L}(\geq 11 \mathrm{ng} / \mathrm{mL})$; for progesterone levels below this cut-off, ongoing pregnancy rate per embryo transfer was $44 \%$ (risk difference $14 \%, P=$ 0.02) (151).

\section{CONCLUSIONS}

In recent years, the freeze-all strategy has emerged as an accepted and valuable alternative to fresh embryo transfer in ART, thanks to increasing demands for fertility treatment and improvements in cryopreservation techniques. The evidence overall indicates that outcomes of eFET are as good as those of fresh embryo transfer in the general population requiring fertility treatment, and in some populations better. This makes it an attractive option in a number of medical or elective scenarios in which it is advantageous to preserve oocytes or embryos and to defer embryo transfer until a later time.

In both fresh and frozen embryo transfers, several factors influence the success of ART. For some of these factors there may be room for optimization before embarking on treatment; however, maternal age is still the most important factor influencing reproductive outcomes in frozen as well as fresh embryo transfer; sperm DNA fragmentation and serum progesterone at peri-implantation are also important factors that are likely to be a focus for research and patient monitoring/screening during the coming years. Thus, recent data support the notion of a significant role for serum progesterone as a biomarker of endometrial receptivity in embryo transfer cycles, and a number of different strategies have been explored in the search for optimal endometrial preparation protocols.

In conclusion, cryopreservation in ART has already substantially changed the therapeutic landscape and continues to evolve as we learn more about ways to optimize the protocols and their applications to specific groups of patients. Going forward, more prospective randomized controlled trials are needed, indications for freeze-all need to be clearly defined, cryopreservation protocols need to be fine-tuned, cost-effectiveness studies are required, and societal aspects must be addressed. Last, but not least, the safety aspects of cryopreservation to both women and their offspring require further scrutiny and long-term assessment.

\section{AUTHOR CONTRIBUTIONS}

$\mathrm{EB}, \mathrm{MD}$, and $\mathrm{PH}$ contributed equally to the publication. All authors have been fully involved in the preparation of the manuscript at all stages from concept to final draft and approval and take accountability for all aspects of the work.

\section{FUNDING}

Funding for medical writing support and journal fees was provided by Preglem S.A., Geneva, Switzerland, part of the Gedeon Richter group.

\section{ACKNOWLEDGMENTS}

Medical writing assistance was provided by Joanne Fitz-Gerald at Fourwave Medical Communications, the funding for which was provided by Preglem S.A., Geneva, Switzerland, part of the Gedeon Richter group. 


\section{REFERENCES}

1. Humaidan P, Polyzos NP, Alsbjerg B, Erb K, Mikkelsen AL, Elbaek HO, et al. GnRHa trigger and individualized luteal phase hCG support according to ovarian response to stimulation: two prospective randomized controlled multi-centre studies in IVF patients. Hum Reprod. (2013) 28:2511-21. doi: 10.1093/humrep/det249

2. Rezazadeh Valojerdi M, Eftekhari-Yazdi P, Karimian L, Hassani F, Movaghar B. Vitrification versus slow freezing gives excellent survival, post warming embryo morphology and pregnancy outcomes for human cleaved embryos. J Assist Reprod Genet. (2009) 26:347-54. doi: 10.1007/s10815-009-9318-6

3. Banker M, Kotdawala A, Gupta R. The impact of vitrification in artificial reproductive technology programmes. Eur Med J. (2017) 2:82-9.

4. Li H, Chian R-C. Mitochondrial dysfunction and age-related oocyte quality. Reprod Dev Med. (2017) 1:45-54. doi: 10.4103/WKMP-0152.210693

5. Thomsen LH, Kesmodel US, Erb K, Bungum L, Pedersen D, Hauge B, et al. The impact of luteal serum progesterone levels on live birth rates-a prospective study of 602 IVF/ICSI cycles. Hum Reprod. (2018) 33:1506-16. doi: 10.1093/humrep/dey226

6. Osman A, Alsomait H, Seshadri S, El-Toukhy T, Khalaf Y. The effect of sperm DNA fragmentation on live birth rate after IVF or ICSI: a systematic review and meta-analysis. Reprod Biomed Online. (2015) 30:1207. doi: 10.1016/j.rbmo.2014.10.018

7. Baker JM, Chase DM, Herbst-Kralovetz MM. Uterine microbiota: residents, tourists, or invaders? Front Immunol. (2018) 9:208. doi: 10.3389/fimmu.2018.00208

8. Trounson A, Mohr L. Human pregnancy following cryopreservation, thawing and transfer of an eight-cell embryo. Nature. (1983) 305:707-9. doi: $10.1038 / 305707 \mathrm{a} 0$

9. Zeilmaker GH, Alberda AT, van Gent I, Rijkmans CM, Drogendijk AC. Two pregnancies following transfer of intact frozen-thawed embryos. Fertil Steril. (1984) 42:293-6. doi: 10.1016/S0015-0282(16)48029-5

10. Griesinger G, Schultz L, Bauer T, Broessner A, Frambach T, Kissler S. Ovarian hyperstimulation syndrome prevention by gonadotropin-releasing hormone agonist triggering of final oocyte maturation in a gonadotropin-releasing hormone antagonist protocol in combination with a "freeze-all" strategy: a prospective multicentric study. Fertil Steril. (2011) 95:2029-33; 33 e1. doi: 10.1016/j.fertnstert.2011.01.163

11. Check JH, Askari HA, Fisher C, Vanaman L. The use of a shared donor oocyte program to evaluate the effect of uterine senescence. Fertil Steril. (1994) 61:252-6. doi: 10.1016/S0015-0282(16)56512-1

12. Akagbosu F, Marcus S, Abusheikha N, Avery S, Brinsden P. Does ovarian hyperstimulation syndrome affect the quality of oocytes? Hum Reprod. (1998) 13:2583-4. doi: 10.1093/humrep/13.9.2583

13. Penzias A, Bendikson K, Butts S, Coutifaris C, Falcone T, Fossum G, et al. The use of preimplantation genetic testing for aneuploidy (PGT-A): a committee opinion. Fertil Steril. (2018) 109:429-36. doi: 10.1016/j.fertnstert.2018.01.002

14. Devroey P, Polyzos NP, Blockeel C. An OHSS-free clinic by segmentation of IVF treatment. Hum Reprod. (2011) 26:2593-7. doi: 10.1093/humrep/der251

15. Roque M, Haahr T, Geber S, Esteves SC, Humaidan P. Fresh versus elective frozen embryo transfer in IVF/ICSI cycles: a systematic review and metaanalysis of reproductive outcomes. Hum Reprod Update. (2019) 25:2-14. doi: 10.1093/humupd/dmy033

16. Shenfield F, de Mouzon J, Scaravelli G, Kupka M, Ferraretti AP, Prados FJ, et al. Oocyte and ovarian tissue cryopreservation in European countries: statutory background, practice, storage and use. Hum Reprod Open. (2017) 2017:hox003. doi: 10.1093/hropen/hox003

17. Kupka MS, D'Hooghe T, Ferraretti AP, de Mouzon J, Erb K, Castilla JA, et al. Assisted reproductive technology in Europe, 2011: results generated from European registers by ESHRE. Hum Reprod. (2016) 31:233-48. doi: 10.1093/humrep/dev319

18. Groenewoud ER, Cohlen BJ, Macklon NS. Programming the endometrium for deferred transfer of cryopreserved embryos: hormone replacement versus modified natural cycles. Fertil Steril. (2018) 109:768-74. doi: 10.1016/j.fertnstert.2018.02.135

19. Maheshwari A, Bhattacharya S. Elective frozen replacement cycles for all: ready for prime time? Hum Reprod. (2013) 28:6-9. doi: 10.1093/humrep/des386
20. Cohen J, Alikani M. The time has come to radically rethink assisted reproduction. Reprod Biomed Online. (2013) 27:323-4. doi: 10.1016/j.rbmo.2013.08.001

21. Ferraretti AP, Gianaroli L, Magli C, Fortini D, Selman HA, Feliciani E. Elective cryopreservation of all pronucleate embryos in women at risk of ovarian hyperstimulation syndrome: efficiency and safety. Hum Reprod. (1999) 14:1457-60. doi: 10.1093/humrep/14.6.1457

22. Shapiro BS, Daneshmand ST, Garner FC, Aguirre M, Hudson C, Thomas S. Evidence of impaired endometrial receptivity after ovarian stimulation for in vitro fertilization: a prospective randomized trial comparing fresh and frozen-thawed embryo transfers in high responders. Fertil Steril. (2011) 96:516-8. doi: 10.1016/j.fertnstert.2011.02.059

23. Shapiro BS, Daneshmand ST, Garner FC, Aguirre M, Hudson C, Thomas S. Evidence of impaired endometrial receptivity after ovarian stimulation for in vitro fertilization: a prospective randomized trial comparing fresh and frozen-thawed embryo transfer in normal responders. Fertil Steril. (2011) 96:344-8. doi: 10.1016/j.fertnstert.2011.05.050

24. Absalan F, Ghannadi A, Kazerooni M. Reproductive outcome following thawed embryo transfer in management of ovarian hyperstimulation syndrome. J Reprod Infertil. (2013) 14:133-7.

25. Chen ZJ, Shi Y, Sun Y, Zhang B, Liang X, Cao Y, et al. Fresh versus frozen embryos for infertility in the polycystic ovary syndrome. N Engl J Med. (2016) 375:523-33. doi: 10.1056/NEJMoa1513873

26. Aghahosseini M, Aleyasin A, Sarfjoo FS, Mahdavi A, Yaraghi M, Saeedabadi H. In vitro fertilization outcome in frozen versus fresh embryo transfer in women with elevated progesterone level on the day of HCG injection: an RCT. Int J Reprod Biomed. (2017) 15:757-62. doi: 10.29252/ijrm.15. 12.757

27. Coates A, Kung A, Mounts E, Hesla J, Bankowski B, Barbieri E, et al. Optimal euploid embryo transfer strategy, fresh versus frozen, after preimplantation genetic screening with next generation sequencing: a randomized controlled trial. Fertil Steril. (2017) 107:723-30.e3. doi: 10.1016/j.fertnstert.2016.12.022

28. Aflatoonian A, Mansoori-Torshizi M, Farid Mojtahedi M, Aflatoonian B, Khalili MA, Amir-Arjmand MH, et al. Fresh versus frozen embryo transfer after gonadotropin-releasing hormone agonist trigger in gonadotropinreleasing hormone antagonist cycles among high responder women: a randomized, multi-center study. Int J Reprod Biomed. (2018) 16:9-18. doi: 10.29252/ijrm.16.1.9

29. Shi Y, Sun Y, Hao C, Zhang H, Wei D, Zhang Y, et al. Transfer of fresh versus frozen embryos in ovulatory women. N Engl J Med. (2018) 378:126-36. doi: 10.1056/NEJMoa1705334

30. Vuong LN, Dang VQ, Ho TM, Huynh BG, Ha DT, Pham TD, et al. IVF transfer of fresh or frozen embryos in women without polycystic ovaries. $N$ Engl J Med. (2018) 378:137-47. doi: 10.1056/NEJMoa1703768

31. Zhang B, Wei D, Legro RS, Shi Y, Li J, Zhang L, et al. Obstetric complications after frozen versus fresh embryo transfer in women with polycystic ovary syndrome: results from a randomized trial. Fertil Steril. (2018) 109:324-9. doi: 10.1016/j.fertnstert.2017.10.020

32. Cobo A, Meseguer M, Remohi J, Pellicer A. Use of cryo-banked oocytes in an ovum donation programme: a prospective, randomized, controlled, clinical trial. Hum Reprod. (2010) 25:2239-46. doi: 10.1093/humrep/deq146

33. Baldwin K, Culley L, Hudson N, Mitchell H, Lavery S. Oocyte cryopreservation for social reasons: demographic profile and disposal intentions of UK users. Reprod Biomed Online. (2015) 31:239-45. doi: 10.1016/j.rbmo.2015.04.010

34. Stoop D, Cobo A, Silber S. Fertility preservation for age-related fertility decline. Lancet. (2014) 384:1311-9. doi: 10.1016/S0140-6736(14) 61261-7

35. Magdi Y, El-Damen A, Fathi AM, Abdelaziz AM, Abd-Elfatah Youssef M, Abd-Allah AA, et al. Revisiting the management of recurrent implantation failure through freeze-all policy. Fertil Steril. (2017) 108:72-7. doi: 10.1016/j.fertnstert.2017.04.020

36. Shapiro BS, Garner FC. Recurrent implantation failure is another indication for the freeze-all strategy. Fertil Steril. (2017) 108:44. doi: 10.1016/j.fertnstert.2017.05.018

37. Mattawanon N, Spencer JB, Schirmer DA 3rd, Tangpricha V. Fertility preservation options in transgender people: a review. Rev Endocr Metab Disord. (2018) 19:231-42. doi: 10.1007/s11154-018-9462-3 
38. Wallace SA, Blough KL, Kondapalli LA. Fertility preservation in the transgender patient: expanding oncofertility care beyond cancer. Gynecol Endocrinol. (2014) 30:868-71. doi: 10.3109/09513590.2014.920005

39. Gromoll J, Tuttelmann F, Kliesch S. Social freezing - the male perspective. Urologe A. (2016) 55:58-62. doi: 10.1007/s00120-015-3943-8

40. American Society for Reproductive Medicine, Society for Assisted Reproductive Technology. Mature oocyte cryopreservation: a guideline. Fertil Steril. (2013) 99:37-43. doi: 10.1016/j.fertnstert.2012.09.028

41. Somigliana E, Vigano P, Filippi F, Papaleo E, Benaglia L, Candiani M, et al. Fertility preservation in women with endometriosis: for all, for some, for none? Hum Reprod. (2015) 30:1280-6. doi: 10.1093/humrep/dev078

42. Oktay K, Bedoschi G, Berkowitz K, Bronson R, Kashani B, McGovern P, et al. Fertility preservation in women with Turner syndrome: a comprehensive review and practical guidelines. J Pediatr Adolesc Gynecol. (2016) 29:409-16. doi: 10.1016/j.jpag.2015.10.011

43. Song WY, Sun YP, Jin HX, Xin ZM, Su YC, Chian RC. Clinical outcome of emergency egg vitrification for women when sperm extraction from the testicular tissues of the male partner is not successful. Syst Biol Reprod Med. (2011) 57:210-3. doi: 10.3109/19396368.2011.566666

44. Argyle CE, Harper JC, Davies MC. Oocyte cryopreservation: where are we now? Hum Reprod Update. (2016) 22:440-9. doi: 10.1093/humupd/dmw007

45. Santos-Ribeiro S, Polyzos NP, Haentjens P, Smitz J, Camus M, Tournaye H, et al. Live birth rates after IVF are reduced by both low and high progesterone levels on the day of human chorionic gonadotrophin administration. Hum Reprod. (2014) 29:1698-705. doi: 10.1093/humrep/deu151

46. Venetis CA, Kolibianakis EM, Bosdou JK, Tarlatzis BC. Progesterone elevation and probability of pregnancy after IVF: a systematic review and meta-analysis of over 60000 cycles. Hum Reprod Update. (2013) 19:433-57. doi: 10.1093/humupd/dmt014

47. Bosch E, Labarta E, Crespo J, Simon C, Remohi J, Jenkins J, et al. Circulating progesterone levels and ongoing pregnancy rates in controlled ovarian stimulation cycles for in vitro fertilization: analysis of over 4000 cycles. Hum Reprod. (2010) 25:2092-100. doi: 10.1093/humrep/deq125

48. Papanikolaou EG, Humaidan P, Polyzos N, Kalantaridou S, Kol S, Benadiva C, et al. New algorithm for OHSS prevention. Reprod Biol Endocrinol. (2011) 9:147. doi: 10.1186/1477-7827-9-147

49. Scaravelli G, Vigiliano V, Mayorga JM, Bolli S, De Luca R, D’Aloja P. Analysis of oocyte cryopreservation in assisted reproduction: the Italian National Register data from 2005 to 2007. Reprod Biomed Online. (2010) 21:496-500. doi: 10.1016/j.rbmo.2010.05.008

50. Blockeel C, Drakopoulos P, Santos-Ribeiro S, Polyzos NP, Tournaye H. A fresh look at the freeze-all protocol: a SWOT analysis. Hum Reprod. (2016) 31:491-7. doi: 10.1093/humrep/dev339

51. Sunkara SK, Rittenberg V, Raine-Fenning N, Bhattacharya S, Zamora J, Coomarasamy A. Association between the number of eggs and live birth in IVF treatment: an analysis of 400135 treatment cycles. Hum Reprod. (2011) 26:1768-74. doi: 10.1093/humrep/der106

52. Polyzos NP, Drakopoulos P, Parra J, Pellicer A, Santos-Ribeiro S, Tournaye $\mathrm{H}$, et al. Cumulative live birth rates according to the number of oocytes retrieved after the first ovarian stimulation for in vitro fertilization/intracytoplasmic sperm injection: a multicenter multinational analysis including approximately 15,000 women. Fertil Steril. (2018) 110:661-70.e1. doi: 10.1016/j.fertnstert.2018.04.039

53. Goldman RH, Racowsky C, Farland LV, Munne S, Ribustello L, Fox JH. Predicting the likelihood of live birth for elective oocyte cryopreservation: a counseling tool for physicians and patients. Hum Reprod. (2017) 32:853-9. doi: 10.1093/humrep/dex008

54. Zhu Q, Chen Q, Wang L, Lu X, Lyu Q, Wang Y, et al. Live birth rates in the first complete IVF cycle among 20687 women using a freeze-all strategy. Hum Reprod. (2018) 33:924-9. doi: 10.1093/humrep/dey044

55. Reddy J, Turan V, Bedoschi G, Moy F, Oktay K. Triggering final oocyte maturation with gonadotropin-releasing hormone agonist $(\mathrm{GnRHa})$ versus human chorionic gonadotropin (hCG) in breast cancer patients undergoing fertility preservation: an extended experience. J Assist Reprod Genet. (2014) 31:927-32. doi: 10.1007/s10815-014-0248-6

56. Abbara A, Vuong LN, Ho VNA, Clarke SA, Jeffers L, Comninos AN, et al. Follicle size on day of trigger most likely to yield a mature oocyte. Front Endocrinol. (2018) 9:193. doi: 10.3389/fendo.2018.00193
57. Xu B, Li Z, Zhang H, Jin L, Li Y, Ai J, et al. Serum progesterone level effects on the outcome of in vitro fertilization in patients with different ovarian response: an analysis of more than 10,000 cycles. Fertil Steril. (2012) 97:1321-7 e1-4. doi: 10.1016/j.fertnstert.2012.03.014

58. Melo MA, Meseguer M, Garrido N, Bosch E, Pellicer A, Remohi J. The significance of premature luteinization in an oocyte-donation programme. Hum Reprod. (2006) 21:1503-7. doi: 10.1093/humrep/dei474

59. Blockeel C, Racca A, De Munck N, Santos-Ribeiro S, Errazuriz Valenzuela J, Drakopoulos P, et al. Impact of serum progesterone on embryo quality and cumulative live birth rate in oocyte donation cycles. Hum Reprod. (2018) 33(Suppl1):i464. doi: 10.1093/humrep/33.Supplement_1.1

60. Racca A, Santos-Ribeiro S, De Munck N, Mackens S, Drakopoulos $\mathrm{P}$, Camus $\mathrm{M}$, et al. Impact of late-follicular phase elevated serum progesterone on cumulative live birth rates: is there a deleterious effect on embryo quality? Hum Reprod. (2018) 33:860-8. doi: 10.1093/humrep/d ey031

61. Nagy B, Poto L, Farkas N, Koppan M, Varnagy A, Kovacs K, et al. Follicular fluid progesterone level associated with fertilization outcome during in vitro fertilization: a systematic review and meta-analysis. Reprod Biomed Online. (2019) 38:871-82. doi: 10.1016/j.rbmo.2018.12.045

62. Baerwald AR, Adams GP, Pierson RA. Characterization of ovarian follicular wave dynamics in women. Biol Reprod. (2003) 69:1023-31. doi: 10.1095/biolreprod.103.017772

63. Cakmak H, Katz A, Cedars MI, Rosen MP. Effective method for emergency fertility preservation: random-start controlled ovarian stimulation. Fertil Steril. (2013) 100:1673-80. doi: 10.1016/j.fertnstert.2013. 07.1992

64. Kim JH, Kim SK, Lee HJ, Lee JR, Jee BC, Suh CS, et al. Efficacy of randomstart controlled ovarian stimulation in cancer patients. J Korean Med Sci. (2015) 30:290-5. doi: 10.3346/jkms.2015.30.3.290

65. von Wolff M, Capp E, Jauckus J, Strowitzki T, Germeyer A. Timing of ovarian stimulation in patients prior to gonadotoxic therapy: an analysis of 684 stimulations. Eur J Obstet Gynecol Reprod Biol. (2016) 199:146-9. doi: 10.1016/j.ejogrb.2016.02.006

66. Danis RB, Pereira N, Elias RT. Random start ovarian stimulation for oocyte or embryo cryopreservation in women desiring fertility preservation prior to gonadotoxic cancer therapy. Curr Pharm Biotechnol. (2017) 18:609-13. doi: 10.2174/1389201018666170808122531

67. Pereira N, Voskuilen-Gonzalez A, Hancock K, Lekovich JP, Schattman GL, Rosenwaks Z. Random-start ovarian stimulation in women desiring elective cryopreservation of oocytes. Reprod Biomed Online. (2017) 35:400-6. doi: 10.1016/j.rbmo.2017.06.002

68. Blockeel C. Initiation of Ovarian Stimulation With Recombinant-Human FSH (Bemfola $\left.{ }^{\circledR}\right)$ in the Late Follicular Phase, a Randomized Controlled Pilot Study. FORWARD (Funding Opportunity for Research Work Advancement in Reproductive Development) Grant Winners 2018: Gedeon Richter (2018). Available online at: http://forwardgrant.com/winners-2018/

69. Ubaldi FM, Capalbo A, Vaiarelli A, Cimadomo D, Colamaria S, Alviggi $\mathrm{C}$, et al. Follicular versus luteal phase ovarian stimulation during the same menstrual cycle (DuoStim) in a reduced ovarian reserve population results in a similar euploid blastocyst formation rate: new insight in ovarian reserve exploitation. Fertil Steril. (2016) 105:1488-95.e1. doi: 10.1016/j.fertnstert.2016.03.002

70. Alsbjerg B, Haahr T, Elbaek HO, Laursen R, Povlsen BB, Humaidan P. Dual stimulation using corifollitropin alfa in 54 Bologna criteria poor ovarian responders-a case series. Reprod Biomed Online. (2019) 38:677-82. doi: 10.1016/j.rbmo.2019.01.007

71. Kuang Y, Chen Q, Fu Y, Wang Y, Hong Q, Lyu Q, et al. Medroxyprogesterone acetate is an effective oral alternative for preventing premature luteinizing hormone surges in women undergoing controlled ovarian hyperstimulation for in vitro fertilization. Fertil Steril. (2015) 104:62-70 e3. doi: 10.1016/j.fertnstert.2015.03.022

72. Zhu X, Zhang X, Fu Y. Utrogestan as an effective oral alternative for preventing premature luteinizing hormone surges in women undergoing controlled ovarian hyperstimulation for in vitro. fertilization. Medicine. (2015) 94:e909. doi: 10.1097/MD.0000000000000909

73. Meyer L, Murphy LA, Gumer A, Reichman DE, Rosenwaks Z, Cholst IN. Risk factors for a suboptimal response to gonadotropin-releasing hormone 
agonist trigger during in vitro. fertilization cycles. Fertil Steril. (2015) 104:637-42. doi: 10.1016/j.fertnstert.2015.06.011

74. Popovic-Todorovic B, Santos-Ribeiro S, De Vos M, Racca A, Drakopoulos P, Thorez Y, et al. Are serum LH levels at the initiation of ovarian stimulation associated with oocyte retrieval yield after GnRH agonist triggering? Hum Reprod. (2018) 33(Suppl 1):i79. doi: 10.1093/humrep/33.Supplement_1.1

75. Lu X, Hong Q, Sun L, Chen Q, Fu Y, Ai A, et al. Dual trigger for final oocyte maturation improves the oocyte retrieval rate of suboptimal responders to gonadotropin-releasing hormone agonist. Fertil Steril. (2016) 106:1356-62. doi: 10.1016/j.fertnstert.2016.07.1068

76. Chang FE, Beall SA, Cox JM, Richter KS, DeCherney AH, Levy MJ. Assessing the adequacy of gonadotropin-releasing hormone agonist leuprolide to trigger oocyte maturation and management of inadequate response. Fertil Steril. (2016) 106:1093-100.e3. doi: 10.1016/j.fertnstert.2016.06.013

77. Herrero L, Martinez M, Garcia-Velasco JA. Current status of human oocyte and embryo cryopreservation. Curr Opin Obstet Gynecol. (2011) 23:245-50. doi: 10.1097/GCO.0b013e32834874e2

78. Cobo A, de los Santos MJ, Castello D, Gamiz P, Campos P, Remohi J. Outcomes of vitrified early cleavage-stage and blastocyst-stage embryos in a cryopreservation program: evaluation of 3,150 warming cycles. Fertil Steril. (2012) 98:1138-46.e1. doi: 10.1016/j.fertnstert.2012.07.1107

79. Wong KM, Mastenbroek S, Repping S. Cryopreservation of human embryos and its contribution to in vitro fertilization success rates. Fertil Steril. (2014) 102:19-26. doi: 10.1016/j.fertnstert.2014.05.027

80. Papaleo E, Pagliardini L, Vanni VS, Delprato D, Rubino P, Candiani M, et al. A direct healthcare cost analysis of the cryopreserved versus fresh transfer policy at the blastocyst stage. Reprod Biomed Online. (2017) 34:19-26. doi: 10.1016/j.rbmo.2016.09.008

81. Roque M, Valle M, Guimaraes F, Sampaio M, Geber S. Cost-effectiveness of the freeze-all policy. JBRA Assist Reprod. (2015) 19:125-30. doi: 10.5935/1518-0557.20150028

82. Song J, Xiang S, Sun Z. Frozen embryo transfer at the cleavage stage can be performed within the first menstrual cycle following the freeze-all strategy without adversely affecting the live birth rate: a STROBE-compliant retrospective study. Medicine. (2019) 98:e17329. doi: 10.1097/MD.0000000000017329

83. Bourdon M, Santulli P, Maignien C, Pocate-Cheriet K, Alwohaibi A, Marcellin L, et al. The interval between oocyte retrieval and frozenthawed blastocyst transfer does not affect the live birth rate and obstetrical outcomes. PLoS ONE. (2018) 13:e0206067. doi: 10.1371/journal.pone.02 06067

84. Higgins C, Healey M, Jatkar S, Vollenhoven B. Interval between IVF stimulation cycle and frozen embryo transfer: is there a benefit to a delay between cycles? Aust N Z J Obstet Gynaecol. (2018) 58:217-21. doi: 10.1111/ajo.12696

85. Kaye L, Marsidi A, Rai P, Thorne J, Nulsen J, Engmann L, et al. Frozen blastocyst transfer outcomes in immediate versus delayed subsequent cycles following GnRH agonist or hCG triggers. J Assist Reprod Genet. (2018) 35:669-75. doi: 10.1007/s10815-017-1111-3

86. Lattes K, Checa MA, Vassena R, Brassesco M, Vernaeve V. There is no evidence that the time from egg retrieval to embryo transfer affects live birth rates in a freeze-all strategy. Hum Reprod. (2017) 32:368-74. doi: 10.1093/humrep/dew306

87. Ozgur K, Bulut $\mathrm{H}$, Berkkanoglu $\mathrm{M}$, Humaidan $\mathrm{P}$, Coetzee $\mathrm{K}$. Frozen embryo transfer can be performed in the cycle immediately following the freeze-all cycle. J Assist Reprod Genet. (2018) 35:135-42. doi: 10.1007/s10815-017-1048-6

88. Santos-Ribeiro S, Polyzos NP, Lan VT, Siffain J, Mackens S, Van Landuyt L, et al. The effect of an immediate frozen embryo transfer following a freezeall protocol: a retrospective analysis from two centres. Hum Reprod. (2016) 31:2541-8. doi: 10.1093/humrep/dew194

89. Maheshwari A, Bhattacharya S, Bowler U, Brison D, Child T, Cole C, et al. Study protocol: E-freeze - freezing of embryos in assisted conception: a randomised controlled trial evaluating the clinical and cost effectiveness of a policy of freezing embryos followed by thawed frozen embryo transfer compared with a policy of fresh embryo transfer, in women undergoing in vitro fertilisation. Reprod Health. (2019) 16:81. doi: 10.1186/s12978-019-0737-2
90. Ishihara O, Araki R, Kuwahara A, Itakura A, Saito H, Adamson GD. Impact of frozen-thawed single-blastocyst transfer on maternal and neonatal outcome: an analysis of 277,042 single-embryo transfer cycles from 2008 to 2010 in Japan. Fertil Steril. (2014) 101:128-33. doi: 10.1016/j.fertnstert.2013.09.025

91. Barsky M, St Marie P, Rahil T, Markenson GR, Sites CK. Are perinatal outcomes affected by blastocyst vitrification and warming? Am J Obstet Gynecol. (2016) 215:603.e1-e5. doi: 10.1016/j.ajog.2016.06.002

92. Sazonova A, Kallen K, Thurin-Kjellberg A, Wennerholm UB, Bergh C. Obstetric outcome in singletons after in vitro fertilization with cryopreserved/thawed embryos. Hum Reprod. (2012) 27:1343-50. doi: 10.1093/humrep/des036

93. Opdahl S, Henningsen AA, Tiitinen A, Bergh C, Pinborg A, Romundstad $\mathrm{PR}$, et al. Risk of hypertensive disorders in pregnancies following assisted reproductive technology: a cohort study from the CoNARTaS group. Hum Reprod. (2015) 30:1724-31. doi: 10.1093/humrep/dev090

94. Pinborg A, Loft A, Aaris Henningsen AK, Rasmussen S, Andersen AN. Infant outcome of 957 singletons born after frozen embryo replacement: the Danish National Cohort Study 1995-2006. Fertil Steril. (2010) 94:1320-7. doi: 10.1016/j.fertnstert.2009.05.091

95. Shih W, Rushford DD, Bourne H, Garrett C, McBain JC, Healy DL, et al. Factors affecting low birthweight after assisted reproduction technology: difference between transfer of fresh and cryopreserved embryos suggests an adverse effect of oocyte collection. Hum Reprod. (2008) 23:1644-53. doi: 10.1093/humrep/den150

96. Pelkonen S, Gissler M, Koivurova S, Lehtinen S, Martikainen H, Hartikainen AL, et al. Physical health of singleton children born after frozen embryo transfer using slow freezing: a 3-year follow-up study. Hum Reprod. (2015) 30:2411-8. doi: 10.1093/humrep/dev203

97. Wennerholm UB, Henningsen AK, Romundstad LB, Bergh C, Pinborg A, Skjaerven R, et al. Perinatal outcomes of children born after frozen-thawed embryo transfer: a Nordic cohort study from the CoNARTaS group. Hum Reprod. (2013) 28:2545-53. doi: 10.1093/humrep/det272

98. Spijkers S, Lens JW, Schats R, Lambalk CB. Fresh and Frozen-Thawed embryo transfer compared to natural conception: differences in perinatal outcome. Gynecol Obstet Invest. (2017) 82:538-46. doi: 10.1159/000468935

99. Kalra SK, Ratcliffe SJ, Coutifaris C, Molinaro T, Barnhart KT. Ovarian stimulation and low birth weight in newborns conceived through in vitro fertilization. Obstet Gynecol. (2011) 118:863-71. doi: 10.1097/AOG.0b013e31822be65f

100. Maheshwari A, Raja EA, Bhattacharya S. Obstetric and perinatal outcomes after either fresh or thawed frozen embryo transfer: an analysis of 112,432 singleton pregnancies recorded in the Human Fertilisation and Embryology Authority anonymized dataset. Fertil Steril. (2016) 106:1703-8. doi: $10.1016 /$ j.fertnstert.2016.08.047

101. Vidal M, Vellve K, Gonzalez-Comadran M, Robles A, Prat M, Torne M, et al. Perinatal outcomes in children born after fresh or frozen embryo transfer: a Catalan cohort study based on 14,262 newborns. Fertil Steril. (2017) 107:940-7. doi: 10.1016/j.fertnstert.2017.01.021

102. Belva F, Bonduelle $M$, Roelants $M$, Verheyen G, Van Landuyt L. Neonatal health including congenital malformation risk of 1072 children born after vitrified embryo transfer. Hum Reprod. (2016) 31:1610-20. doi: 10.1093/humrep/dew103

103. Maheshwari A, Pandey S, Shetty A, Hamilton M, Bhattacharya S. Obstetric and perinatal outcomes in singleton pregnancies resulting from the transfer of frozen thawed versus fresh embryos generated through in vitro fertilization treatment: a systematic review and metaanalysis. Fertil Steril. (2012) 98:368-77.e1-9. doi: 10.1016/j.fertnstert.2012. 05.019

104. Mateizel I, Santos-Ribeiro S, Done E, Van Landuyt L, Van de Velde H, Tournaye $\mathrm{H}$, et al. Do ARTs affect the incidence of monozygotic twinning? Hum Reprod. (2016) 31:2435-41. doi: 10.1093/humrep/dew216

105. Maheshwari A, Pandey S, Amalraj Raja E, Shetty A, Hamilton M, Bhattacharya S. Is frozen embryo transfer better for mothers and babies? Can cumulative meta-analysis provide a definitive answer? Hum Reprod Update. (2018) 24:35-58. doi: 10.1093/humupd/dmx031

106. Luke B. Pregnancy and birth outcomes in couples with infertility with and without assisted reproductive technology: with an emphasis on 
US population-based studies. Am J Obstet Gynecol. (2017) 217:270-81. doi: 10.1016/j.ajog.2017.03.012

107. Pelkonen S, Koivunen R, Gissler M, Nuojua-Huttunen S, Suikkari AM, Hyden-Granskog C, et al. Perinatal outcome of children born after frozen and fresh embryo transfer: the Finnish cohort study 1995-2006. Hum Reprod. (2010) 25:914-23. doi: 10.1093/humrep/dep477

108. Pinborg A, Henningsen AA, Loft A, Malchau SS, Forman J, Andersen AN. Large baby syndrome in singletons born after frozen embryo transfer (FET): is it due to maternal factors or the cryotechnique? Hum Reprod. (2014) 29:618-27. doi: 10.1093/humrep/det440

109. Pinborg A, Wennerholm UB, Romundstad LB, Loft A, Aittomaki K, Soderstrom-Anttila V, et al. Why do singletons conceived after assisted reproduction technology have adverse perinatal outcome? Systematic review and meta-analysis. Hum Reprod Update. (2013) 19:87-104. doi: 10.1093/humupd/dms044

110. von Versen-Hoynck F, Schaub AM, Chi YY, Chiu KH, Liu J, Lingis M, et al. Increased preeclampsia risk and reduced aortic compliance with in vitro fertilization cycles in the absence of a corpus luteum. Hypertension. (2019) 73:640-9. doi: 10.1161/HYPERTENSIONAHA.118.12043

111. Cobo A, Garcia-Velasco J, Domingo J, Pellicer A, Remohi J. Elective and onco-fertility preservation: factors related to IVF outcomes. Hum Reprod. (2018) 33:2222-31. doi: 10.1093/humrep/dey321

112. Pujol A, Zamora MJ, Obradors A, Garcia D, Rodriguez A, Vassena R. Comparison of two different oocyte vitrification methods: a prospective, paired study on the same genetic background and stimulation protocol. Hum Reprod. (2019) 34:989-97. doi: 10.1093/humrep/dez045

113. Fleming TP, Watkins AJ, Velazquez MA, Mathers JC, Prentice AM, Stephenson J, et al. Origins of lifetime health around the time of conception: causes and consequences. Lancet. (2018) 391:1842-52. doi: 10.1016/S0140-6736(18)30312-X

114. Hanson MA, Gluckman PD. Early developmental conditioning of later health and disease: physiology or pathophysiology? Physiol Rev. (2014) 94:1027-76. doi: 10.1152/physrev.00029.2013

115. Hiura H, Hattori $H$, Kobayashi $N$, Okae H, Chiba H, Miyauchi $\mathrm{N}$, et al. Genome-wide microRNA expression profiling in placentae from frozen-thawed blastocyst transfer. Clin Epigenetics. (2017) 9:79. doi: 10.1186/s13148-017-0379-6

116. Osman E, Franasiak J, Scott R. Oocyte and embryo manipulation and epigenetics. Semin Reprod Med. (2018) 36:e1-9. doi: 10.1055/s-0039-1688801

117. Chen H, Zhang L, Deng T, Zou P, Wang Y, Quan F, et al. Effects of oocyte vitrification on epigenetic status in early bovine embryos. Theriogenology. (2016) 86:868-78. doi: 10.1016/j.theriogenology.2016.03.008

118. Cheng KR, Fu XW, Zhang RN, Jia GX, Hou YP, Zhu SE. Effect of oocyte vitrification on deoxyribonucleic acid methylation of H19, Peg3, and Snrpn differentially methylated regions in mouse blastocysts. Fertil Steril. (2014) 102:1183-90.e3. doi: 10.1016/j.fertnstert.2014.06.037

119. Yao J, Geng L, Huang R, Peng W, Chen X, Jiang X, et al. Effect of vitrification on in vitro development and imprinted gene Grb10 in mouse embryos. Reproduction. (2017) 154:97-105. doi: 10.1530/REP-16-0480

120. De Munck N, Petrussa L, Verheyen G, Staessen C, Vandeskelde Y, Sterckx J, et al. Chromosomal meiotic segregation, embryonic developmental kinetics and DNA (hydroxy)methylation analysis consolidate the safety of human oocyte vitrification. Mol Hum Reprod. (2015) 21:535-44. doi: 10.1093/molehr/gav013

121. Cobo A, Serra V, Garrido N, Olmo I, Pellicer A, Remohi J. Obstetric and perinatal outcome of babies born from vitrified oocytes. Fertil Steril. (2014) 102:1006-15.e4. doi: 10.1016/j.fertnstert.2014.06.019

122. Roque M, Valle M, Guimaraes F, Sampaio M, Geber S. Freeze-all policy: fresh vs. frozen-thawed embryo transfer. Fertil Steril. (2015) 103:1190-3. doi: 10.1016/j.fertnstert.2015.01.045

123. Celada P, Bosch E, De Los Santos MJ, Giles J, Pellicer A. Elective frozen embryo transfer does not improve reproductive outcome in normo-responder patients. Hum Reprod. (2015) 30(Suppl 1):1112-13. doi: 10.1093/humrep/30.Supplement_1.1

124. Labarta E, Martinez-Conejero JA, Alama P, Horcajadas JA, Pellicer A, Simon C, et al. Endometrial receptivity is affected in women with high circulating progesterone levels at the end of the follicular phase: a functional genomics analysis. Hum Reprod. (2011) 26:1813-25. doi: 10.1093/humrep/der126
125. Bhattacharya S. Maternal and perinatal outcomes after fresh versus frozen embryo transfer-what is the risk-benefit ratio? Fertil Steril. (2016) 106:241-3. doi: 10.1016/j.fertnstert.2016.06.038

126. Evans J, Hannan NJ, Edgell TA, Vollenhoven BJ, Lutjen PJ, Osianlis T, et al. Fresh versus frozen embryo transfer: backing clinical decisions with scientific and clinical evidence. Hum Reprod Update. (2014) 20:808-21. doi: 10.1093/humupd/dmu027

127. Ozgur K, Berkkanoglu M, Bulut H, Humaidan P, Coetzee K. Perinatal outcomes after fresh versus vitrified-warmed blastocyst transfer: retrospective analysis. Fertil Steril. (2015) 104:899-907.e3. doi: 10.1016/j.fertnstert.2015.06.031

128. Shapiro BS, Daneshmand ST, Garner FC, Aguirre M, Hudson C. Clinical rationale for cryopreservation of entire embryo cohorts in lieu of fresh transfer. Fertil Steril. (2014) 102:3-9. doi: 10.1016/j.fertnstert.2014.04.018

129. Yding Andersen C, Bungum L, Nyboe Andersen A, Humaidan P. Preovulatory progesterone concentration associates significantly to follicle number and LH concentration but not to pregnancy rate. Reprod Biomed Online. (2011) 23:187-95. doi: 10.1016/j.rbmo.2011.04.003

130. Requena A, Cruz M, Bosch E, Meseguer M, Garcia-Velasco JA. High progesterone levels in women with high ovarian response do not affect clinical outcomes: a retrospective cohort study. Reprod Biol Endocrinol. (2014) 12:69. doi: 10.1186/1477-7827-12-69

131. Rackow BW, Jorgensen E, Taylor HS. Endometrial polyps affect uterine receptivity. Fertil Steril. (2011) 95:2690-2. doi: 10.1016/j.fertnstert. 2010.12.034

132. Strandell A, Lindhard A, Waldenstrom U, Thorburn J. Hydrosalpinx and IVF outcome: cumulative results after salpingectomy in a randomized controlled trial. Hum Reprod. (2001) 16:2403-10. doi: 10.1093/humrep/16. 11.2403

133. Park CW, Choi MH, Yang KM, Song IO. Pregnancy rate in women with adenomyosis undergoing fresh or frozen embryo transfer cycles following gonadotropin-releasing hormone agonist treatment. Clin Exp Reprod Med. (2016) 43:169-73. doi: 10.5653/cerm.2016.43.3.169

134. Franasiak JM, Ruiz-Alonso M, Scott RT, Simon C. Both slowly developing embryos and a variable pace of luteal endometrial progression may conspire to prevent normal birth in spite of a capable embryo. Fertil Steril. (2016) 105:861-6. doi: 10.1016/j.fertnstert.2016.02.030

135. Loutradi KE, Kolibianakis EM, Venetis CA, Papanikolaou EG, Pados G, Bontis I, et al. Cryopreservation of human embryos by vitrification or slow freezing: a systematic review and meta-analysis. Fertil Steril. (2008) 90:186-93. doi: 10.1016/j.fertnstert.2007.06.010

136. Cobo A, Kuwayama M, Perez S, Ruiz A, Pellicer A, Remohi J. Comparison of concomitant outcome achieved with fresh and cryopreserved donor oocytes vitrified by the Cryotop method. Fertil Steril. (2008) 89:1657-64. doi: $10.1016 /$ j.fertnstert.2007.05.050

137. Rienzi L, Romano S, Albricci L, Maggiulli R, Capalbo A, Baroni E, et al. Embryo development of fresh 'versus' vitrified metaphase II oocytes after ICSI: a prospective randomized sibling-oocyte study. Hum Reprod. (2010) 25:66-73. doi: 10.1093/humrep/dep346

138. Parmegiani L, Cognigni GE, Bernardi S, Cuomo S, Ciampaglia W, Infante $\mathrm{FE}$, et al. Efficiency of aseptic open vitrification and hermetical cryostorage of human oocytes. Reprod Biomed Online. (2011) 23:505-12. doi: 10.1016/j.rbmo.2011.07.003

139. Alsbjerg B, Polyzos NP, Elbaek HO, Povlsen BB, Andersen CY, Humaidan $P$. Increasing vaginal progesterone gel supplementation after frozen-thawed embryo transfer significantly increases the delivery rate. Reprod Biomed Online. (2013) 26:133-7. doi: 10.1016/j.rbmo.2012.10.012

140. Hull MG, Savage PE, Bromham DR, Ismail AA, Morris AF. The value of a single serum progesterone measurement in the midluteal phase as a criterion of a potentially fertile cycle ("ovulation") derived form treated and untreated conception cycles. Fertil Steril. (1982) 37:355-60. doi: 10.1016/S0015-0282(16)46095-4

141. Large MJ, DeMayo FJ. The regulation of embryo implantation and endometrial decidualization by progesterone receptor signaling. Mol Cell Endocrinol. (2012) 358:155-65. doi: 10.1016/j.mce.2011.07.027

142. Labarta E, Mariani G, Holtmann N, Celada P, Remohi J, Bosch E. Low serum progesterone on the day of embryo transfer is associated with a diminished ongoing pregnancy rate in oocyte donation cycles after artificial 
endometrial preparation: a prospective study. Hum Reprod. (2017) 32:243742. doi: 10.1093/humrep/dex316

143. Humaidan P, Bredkjaer HE, Bungum L, Bungum M, Grondahl ML, Westergaard L, et al. GnRH agonist (buserelin) or hCG for ovulation induction in GnRH antagonist IVF/ICSI cycles: a prospective randomized study. Hum Reprod. (2005) 20:1213-20. doi: 10.1093/humrep/d eh765

144. Humaidan P, Ejdrup Bredkjaer H, Westergaard LG, Yding Andersen C. 1,500 IU human chorionic gonadotropin administered at oocyte retrieval rescues the luteal phase when gonadotropin-releasing hormone agonist is used for ovulation induction: a prospective, randomized, controlled study. Fertil Steril. (2010) 93:847-54. doi: 10.1016/j.fertnstert.2008.12.042

145. Young SL, Savaris RF, Lessey BA, Sharkey AM, Balthazar U, Zaino RJ, et al. Effect of randomized serum progesterone concentration on secretory endometrial histologic development and gene expression. Hum Reprod. (2017) 32:1903-14. doi: 10.1093/humrep/dex252

146. Ghobara T, Gelbaya TA, Ayeleke RO. Cycle regimens for frozenthawed embryo transfer. Cochrane Database Syst Rev. (2017) 7:Cd003414. doi: 10.1002/14651858.CD003414.pub3

147. Bjuresten K, Landgren BM, Hovatta O, Stavreus-Evers A. Luteal phase progesterone increases live birth rate after frozen embryo transfer. Fertil Steril. (2011) 95:534-7. doi: 10.1016/j.fertnstert.2010. 05.019

148. Kim CH, Lee YJ, Lee KH, Kwon SK, Kim SH, Chae HD, et al. The effect of luteal phase progesterone supplementation on natural frozenthawed embryo transfer cycles. Obstet Gynecol Sci. (2014) 57:291-6. doi: $10.5468 /$ ogs.2014.57.4.291

149. Devine K, Richter KS, Widra EA, McKeeby JL. Vitrified blastocyst transfer cycles with the use of only vaginal progesterone replacement with Endometrin have inferior ongoing pregnancy rates: results from the planned interim analysis of a three-arm randomized controlled noninferiority trial. Fertil Steril. (2018) 109:266-75. doi: 10.1016/j.fertnstert.2017.11.004

150. Cedrin-Durnerin I, Isnard T, Mahdjoub S, Sonigo C, Seroka A, Comtet M, et al. Serum progesterone concentration and live birth rate in frozen-thawed embryo transfers with hormonally prepared endometrium. Reprod Biomed Online. (2019). doi: 10.1016/j.rbmo.2018.11.026

151. Alsbjerg B, Thomsen L, Elbaek HO, Laursen R, Povlsen BB, Haahr $\mathrm{T}$, et al. Progesterone levels on pregnancy test day after hormone replacement therapy-cryopreserved embryo transfer cycles and related reproductive outcomes. Reprod Biomed Online. (2018) 37:641-7. doi: 10.1016/j.rbmo.2018.08.022

Conflict of Interest: EB has received a research grant from Finox (part of the Gedeon Richter group); participated in advisory boards for Finox, MSD, and Roche Diagnostics; and participated in speakers bureaux and received honoraria from Ferring, Merck Serono, and MSD. MD has received lecture fees from Besins Healthcare, Cook Medical, Ferring, Gedeon Richter, and MSD. PH has received unrestricted research grants and honoraria from Ferring, Gedeon Richter, IBSA, Merck, and MSD.

The reviewer GB declared a past co-authorship with one of the authors $\mathrm{PH}$ to the handling editor.

Copyright $\odot 2020$ Bosch, De Vos and Humaidan. This is an open-access article distributed under the terms of the Creative Commons Attribution License (CC BY). The use, distribution or reproduction in other forums is permitted, provided the original author(s) and the copyright owner(s) are credited and that the original publication in this journal is cited, in accordance with accepted academic practice. No use, distribution or reproduction is permitted which does not comply with these terms. 